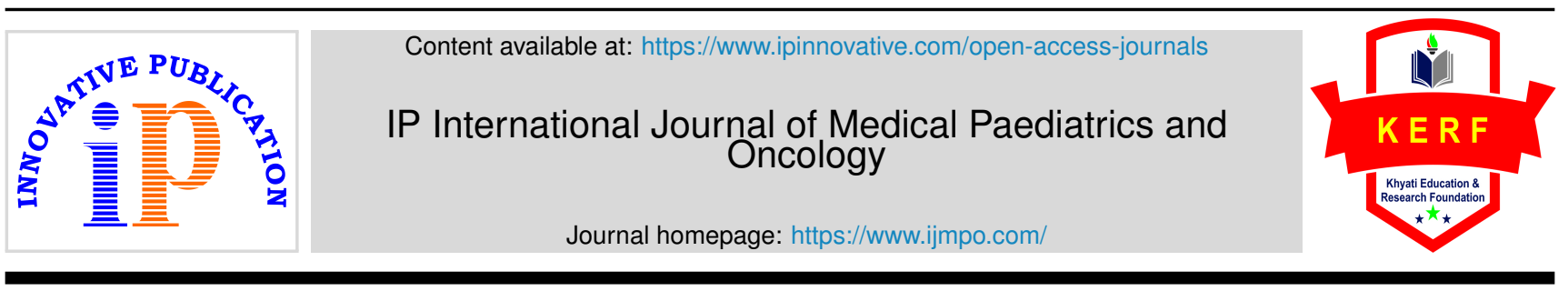

Original Research Article

\title{
Outcome assessment for pyeloplasty in pediatric age group on the basis of ultrasonography
}

\author{
RK Maurya ${ }^{1}$, RK Tripathi ${ }^{1}$, Ajay Kumar ${ }^{1}$, Pinaki Ranjan Debnath ${ }^{2}$, Vasu Gautam ${ }^{2, *}$, \\ Arnab Kumar Saha ${ }^{2}$ \\ ${ }^{1}$ Dept. of Surgery, Ganesh Shankar Vidyarthi Memorial Medical College, Kanpur, Uttar Pradesh, India \\ ${ }^{2}$ Dept. of Pediatric Surgery, ABVIMS and DR RML Hospital, New Delhi, India
}

\section{A R T I C L E I N F O}

\section{Article history:}

Received 05-06-2021

Accepted 15-06-2021

Available online 03-08-2021

\section{Keywords:}

DTPA

PUJ obstruction

Pyeloplasty

\begin{abstract}
A B S T R A C T
Objective: At present, duration and methods of radiographic follow-up after pediatric pyeloplasty are not well defined. We prospectively studied pediatric age group patients to assess outcome for cases of pyeloplasty on the basis of ultrasonography and DTPA scan.

Materials and Methods: We assessed all cases of PUJ obstruction in age group 0-18 years, who got admitted in LLR hospital, Kanpur and underwent pyeloplasty. Patients were excluded if cause of pyeloplasty was acquired. Preoperatively patients underwent clinical evaluation with history and examination followed by radiological investigations including Renal USG \& DTPA scan. All patients were followed up postoperatively at 3, 6, 9 \& 12 months. In USG, renal parenchyma thickness, antero-posterior diameter of renal pelvis was assessed. In DTPA scan, differential renal function was assessed. Data of USG and DTPA scan were statistically compared.

Result: 32 patients who underwent pyeloplasty at a median age of 4.2 years were studied. Follow-up was done for 1 year. On the basis of our study, DTPA scan is better than renal USG to assess functional outcome after pyeloplasty in pediatric age group up to 6 months during follow-up. But results are comparable for follow-up during $9 \& 12$ months postoperatively. The results of our study show that in the first 6 months, renal USG is not as much informative as DTPA scan to assess functional outcome after pyeloplasty but after 6 months, renal USG is equally effective as DTPA scan.

Conclusion: Our study concludes that for poor resource countries, renal USG can be used to assess functional outcome after pyeloplasty in pediatric age group for post-operative follow-up, instead of costly \& scarcely available investigation like Renal DTPA scan.

(C) This is an open access article distributed under the terms of the Creative Commons Attribution License (https://creativecommons.org/licenses/by/4.0/) which permits unrestricted use, distribution, and reproduction in any medium, provided the original author and source are credited.
\end{abstract}

\section{Introduction}

Pelviureteric junction obstruction (PUJO), or Ureteropelvic junction obstruction (UPJO), is defined as obstruction to the flow of urine from the renal pelvis into the proximal upper ureter. This obstruction can lead to an increase in backpressure on the kidney, hydronephrosis and progressive damage to the kidney function. ${ }^{1-5}$

Causes of PUJO may be divided as Congenital \& Acquired or Intrinsic \& Extrinsic. Most hydronephrosis are

\footnotetext{
* Corresponding author.

E-mail address: vasugautam91@gmail.com (V. Gautam).
}

diagnosed antenatally using USG scans at 18- 20 weeks. Prior to the advent of ultrasonographic scanning, the most common presentation of PUJ Obstruction was pain. An abdominal mass or hematuria following a minor trauma may be the presenting complaint in some pediatric patients. Some hydronephrosis only come to light as an incidental finding when investigating for a cause of abdominal pain.

Patients with significantly impaired renal drainage or progressive deterioration of renal function are the candidates for surgical intervention. Other indications for active intervention are to relieve pain or treat pathologies secondary to obstruction such as calculi and infections. ${ }^{6,7}$ 
In up to $98 \%$ of patients, improvement in the renal dilatation and excretion pattern in seen following pyeloplasty. ${ }^{8}$ Though there is high reported success rate of pyeloplasty in patients with PUJ obstruction, there are no established recommendations for follow-up modality or timing of imaging after pediatric pyeloplasty. Many modalities have been suggested, including intravenous pyelography (IVP), radio nucleotide renography, magnetic resonance urography ${ }^{9}$ and ultrasonography (USG), either alone or in combination at various time intervals.

USG and diuretic renal scintigraphy (RS) are the most widely used investigations for diagnosis and postoperative follow-up. ${ }^{10}$ The success of pyeloplasty is based on clinical improvement, the serial USG improvement of hydronephrosis and improved drainage on renal scintigraphy scan with possible recovery of differential renal function (DRF). However, as renal scan is available only at apex medical center in our country; we compared renal USG \& DTPA scan for follow up for outcome assessment of pyeloplasty.

\section{Materials and Methods}

The study titled "Outcome assessment for pyeloplasty in pediatric age group on the basis of ultrasonography and DTPA scan" is a prospective study, which was conducted on the pediatric patients admitted in the General Surgery, Department of LLR Hospital, GSVM Medical College, Kanpur with the diagnosis of Pelviureteric junction obstruction (PUJO) between October 2017 to October 2019.The patients were selected for surgery after clinical, ultrasonological \& nuclear scan evaluation showing the pelviureteric junction obstruction (PUJO).

\subsection{Inclusion criteria}

1. Patient with Pelviureteric junction (PUJ) obstruction on the basis of Ultrasonography \& DTPA scan.

2. Age of patients in between $0-18$ years.

3. Complete written informed consent from acknowledging the awareness of the alternative treatments and risk involvement.

\subsection{Exclusion criteria}

1. Patients whose age was more than 18 years.

2. Patients having acquired causes of PUJ obstruction like due to stone, trauma or iatrogenic causes.

All patients in study had undergone renal USG and DTPA scan. Then all of patient had undergone Anderson Hynes' Dismembered pyeloplasty by open method. Most of the patients were discharged on $10^{t h}$ post-op day after removing drain and stitches; except those who had complications. Follow-up visit was on 3, 6, 9 \& 12 months.
In each follow-up patient was evaluated for any complain, Renal USG and DTPA scan.

Renal USG was done under following points-

1. Cortical thickness at-Upper pole, Middle pole \& Lower pole.

2. Pelvis AP diameter.

DTPA scan to assess functional status of kidney by differential renal function (DRF). Patient's data was collected according to written proforma filled by the residents of the department of surgery. Data was statistically analyzed using the Wilcoxon signed ranks test.

Written informed consent of all patients was taken. Institutional ethics committee approval was obtained.

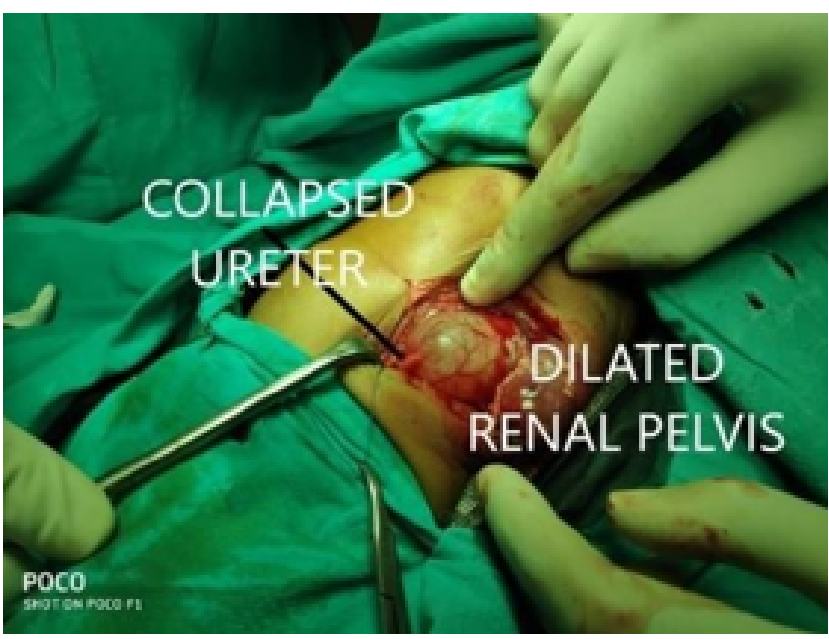

Fig. 1: Intra-operative picture of Anderson Hynes' dismembered Pyeloplasty

\section{Result}

A total of 32 children were studied in our study with the mean age of 4.2 years. Most common age group was 1-6 years $(56 \%)$. Male to female ratio observed in our study is 2.55. All patients involved were unilateral cases of PUJ obstruction. There was a Left preponderance, with Left to Right ratio 1.9:1. Main presenting feature was abdominal lump mainly in the flank region (47\%) followed by flank pain $(37 \%)$. $16 \%$ patients were asymptomatic at the time of presentation. These patients were diagnosed antenatally during routine antenatal USG.

In postoperative follow up, $15 \%$ patients presented with wound dehiscence; $6 \%$ patient presented with prolonged output through drain. No incidence of any other complication, like Secondary PUJ Obstruction, hypertension, urinoma formation was observed in any patient during follow-up for 1 year

At 3 months, 19\% $(\mathrm{n}=06)$ patient showed improvement, while in $81 \%(n=26)$, renal parenchymal thickness remained 
Table 1: Post-operative result based on renal parenchymal thickness on USG

\begin{tabular}{ll}
\hline Improved & $\begin{array}{l}\text { Increase of more than } 2 \mathrm{~mm} \text { in next follow-up } \\
\text { i.e.,3months }\end{array}$ \\
Same & $\begin{array}{l}\text { Upto } 2 \mathrm{~mm} \text { increment in next follow-up } \\
\text { Decreased renal parenchymal thickness in } \\
\text { next follow-up }\end{array}$ \\
\end{tabular}

same. At 6 months, 69\% $(n=22)$, at 9 months $94 \%(n=30)$, at 12 months $100 \%(n=32)$ patients showed improvement in renal parenchymal thickness.

Table 2: Post-operative result based on ap pelvic diameter on USG

$\begin{array}{ll}\text { Improved } & \begin{array}{l}\text { decrease of } 5 \mathrm{~mm} \text { in AP diameter of Renal } \\ \text { pelvis in next follow-up i.e., } 3 \text { months }\end{array} \\ \text { Same } & \text { Upto } 5 \mathrm{~mm} \text { decrement in next follow-up } \\ \text { Worst } & \begin{array}{l}\text { Increased AP diameter of Renal pelvis in } \\ \text { next follow-up }\end{array}\end{array}$

At 3 months, 44\% $(n=14)$ patients showed improvement in AP pelvic diameter i.e. AP pelvic diameter decrease, while in $56 \%(\mathrm{n}=18)$ patients, AP pelvic diameter was same. At 6 months, 69\% $(n=22)$, at 9 months $88 \%(n=28)$ and at 12 months $100 \%(n=32)$ patients showed improvement in AP pelvic diameter i.e., decrease in AP pelvic diameter.

Table 3: Post-operative result based on differential renal function (DRF) on DTPA scan

\begin{tabular}{ll}
\hline Improved & $\begin{array}{l}\text { Increase of DRF by 5\% in next follow-up i.e. } \\
\text { 3months }\end{array}$ \\
Same & Less than 5\% increment in next follow-up \\
Worst & Decrease in DRF in next follow-up \\
\hline
\end{tabular}

At 3 months, $75 \%(n=24)$ patients showed improvement in Differential Renal Function (DRF), while in $25 \%(n=08)$ patients, DRF was same. At 6 months $90 \%(n=29)$, at 9 months $96 \%(n=31)$ and at 12 months all patients i.e. $100 \%$ $(n=32)$ showed improvement in Differential Renal Function (DRF).

On comparing Renal USG data i.e. AP pelvic diameter \& Renal parenchymal thickness during follow-up, data is statistically not significant ( $p$ value $>0.05$ ). Hence, on renal USG, either AP pelvic diameter \& renal parenchymal thickness can be used to assess outcome of pyeloplasty during follow-up within 12 months.

At 3 months \& 6 months, on comparing AP with DRF \& RPT with DRF; P-value is $<0.05$, showing DTPA (DRF) is significantly better than USG to assess outcome during 3 month \& 6 months follow up. While at 9 months \& 12 months the comparison shows no significant difference (P-value is $>0.05$ for all values) showing that USG and DTPA are comparable during 9 months and 12 months.

\section{Discussion}

Postoperative follow up with imaging after pyeloplasty to diagnose obstruction early is important so that intervention can be taken to prevent further nephron loss in case of an unsuccessful pyeloplasty. In post-pyeloplasty follow-up, the most widely used investigations are ultrasonography and renal scintigraphy scan. However, there is variation in modality and frequency of imaging follow-up. ${ }^{11}$

Contemporary series on pediatric pyeloplasty have revealed high success rates, although differing protocols exist regarding imaging surveillance. ${ }^{12-21}$

USG has been used to assess outcome after pyeloplasty by measuring changes in the AP pelvic diameter. It has been suggested that if postoperative USG is revealing downgrading of AP pelvic diameter, patient may not require renograms in follow-up to rule out the obstruction. USG has the disadvantages of operator variability, slower improvement in hydronephrosis, and the difficulties of differentiating between a dilated and an obstructed renal pelvicalyceal system. Some other confounding factors in USG that may affect the findings are the level of preUSG hydration or the amount of urine in the bladder. Additionally, surgical reduction of the renal pelvis can be mistaken as true improvement on USG.

Postoperative diuretics renogram is generally used to assess relief of obstruction and functional recovery. Most published data demonstrate its superiority in the ability to determine obstruction though there are also some arguments against it. Renal scintigraphy showing improved or stable function and better drainage can be considered as documented evidence of successful surgery and is usually performed as a baseline to subjectively document the surgical outcome. ${ }^{22}$

Many studies have questioned the use of early postoperative renography after pediatric pyeloplasty and advocated the use of a sentinel USG to determine if renography is necessary.

Almodhen et al. reported on 97 patients who underwent 101 pyeloplasties with a mean follow-up of 4.5 years. ${ }^{23} \mathrm{Of}$ the 91 kidneys with improvement on postoperative USG, $2(2 \%)$ exhibited an obstructive pattern on renography, although both spontaneously improved during follow-up. ${ }^{23}$ Hydronephrosis was downgraded in 46 kidneys, and none of these kidneys exhibited an obstructive postoperative scan. ${ }^{23}$ Of the 10 kidneys with worsened or no improvement on postoperative USG, 4 (40\%) had an obstructive renogram, of which 2 were treated with a subsequent procedure. ${ }^{23}$ They conclude that those with preoperative function $<45 \%$ may exhibit functional changes $>5 \%$ that can be determined by postoperative RS. ${ }^{23}$

Cost et al. observed similar findings in 49 patients undergoing open pyeloplasty who underwent US and renography at 3 months. ${ }^{24}$ Of the 42 children with stable or improved hydronephrosis, 41 had stable function, and 
Table 4: Statistic comparison of renal usg data during follow- up

\begin{tabular}{lcccc}
\hline Post-operative follow-up & At 3 months & At 6 months & At 9 months & At 12 months \\
Improved A P pelvic diameter & $44 \%$ & $69 \%$ & $88 \%$ & $97 \%$ \\
Improved Renal parenchymal thickness & $29 \%$ & $69 \%$ & $94 \%$ & $100 \%$ \\
P value & 0.216 & 1 & 0.405 & 0.327 \\
\hline
\end{tabular}

Table 5: Statistical comparison of USG and DTPA scan

\begin{tabular}{lccccc}
\hline $\begin{array}{l}\text { Post- operative } \\
\text { follow-up time } \\
\text { (in months) }\end{array}$ & $\begin{array}{c}\text { AP Pelvic } \\
\text { Diameter (AP) }\end{array}$ & $\begin{array}{c}\text { USG } \\
\text { Parenchymal } \\
\text { thickness (RPT) }\end{array}$ & $\begin{array}{c}\text { DTPA } \\
\text { Differential Renal } \\
\text { Function (DRF) }\end{array}$ & $\begin{array}{c}\text { P-value } \\
\text { AP \& DRF }\end{array}$ & RPT \& DRF \\
3 Months & $44 \%$ & $29 \%$ & $75 \%$ & 0.0122 & 0.0003 \\
6 Months & $69 \%$ & $69 \%$ & $90 \%$ & 0.0390 & 0.0390 \\
9 Months & $88 \%$ & $94 \%$ & $96 \%$ & 0.2419 & 0.7157 \\
12 Months & $97 \%$ & $100 \%$ & $100 \%$ & 0.3273 & No difference \\
\hline
\end{tabular}

one had low function (32\% split function) preoperatively but remained stable ( $21 \%$ split function) at longer follow-up. ${ }^{24}$ Of the 7 remaining patients with increased hydronephrosis, 2 had worse renal function. ${ }^{24}$

Van den Hoek et al. reported that SRF remained unchanged within the $5 \%$ range in 75 of 87 patients $(86 \%)$ with initial preoperative function $>40 \% .^{22}$ In that series, only 3 patients $(3 \%)$ demonstrated significant deterioration to $<40 \%$, while 27 of 51 patients $(53 \%)$ with initial function $<40 \%$ exhibited changes $>5 \%$ following surgery. ${ }^{22}$ Moreover, it was observed that SRF after pyeloplasty remained unchanged at 5-7 years compared to the initial 9-month postoperative RS. ${ }^{22}$ Thus, repeat RS at 5-7 years after pyeloplasty was not justified. ${ }^{22}$

Pohl et al., suggested that follow-up can be discontinued as early as 3 months postoperatively if diuretic renogram show $\mathrm{t} \frac{1}{2}<20 \mathrm{~min} .{ }^{18}$ Their data indicate that when an unobstructed 3 months renogram is followed by 1 -year renogram, the second renogram never shows deterioration in drainage, and therefore, is not necessary. ${ }^{8}$ Tveter et al. also noted the similar observations. ${ }^{25}$ Similarly, our data reveal that if SRF was improved at 3 months than it never shows deterioration in renogram over next 1 year.

Psooy et al. showed that after an unobstructed diuretic renogram, recurrence of the obstruction was unlikely and did not justify a long-term follow-up. ${ }^{26}$ They followed their patients radiographically with excretory urography (IVP) at 2months; renal USG at 6 month and RS at 1 year. ${ }^{26}$

O'Reilly et al. used a repeat $\mathrm{RS}$ in 24 patients at 6-19 years after surgery and concluded that the results were durable. 27

Chandrasekharam et al. reported that in 68 children with symptomatic pelviureteric junction obstruction, RSs were taken 3 months, 1, 2, and 5 years after surgery, and it was concluded that in patients with impaired preoperative function, the improvement in SRF continued until 1 year after surgery. ${ }^{28}$ There was no further improvement after that period, and the DRF remained stable. ${ }^{28}$
The overall success rate with the Anderson Hynes Dismembered pyeloplasty repair is quite satisfactory 29,30 with all patients in our study showing improvement.

However, there are no set criteria for follow-up or even for success. Although there is no protocol for follow-up; postoperative evaluation includes Renal USG for AP diameter of renal pelvis \& renal parenchymal thickness, along with renal scanning by DTPA scan. In most cases, dismembered pyeloplasty improves the degree of hydronephrosis and DRF on the renogram. Symptoms of abdominal lump, pain, infection, and hematuria, if present before surgery, resolve along with the improvement of hydronephrosis.

On the basis of our study, in first 6 months Renal USG is not as much informative as DTPA scan to assess functional outcome after pyeloplasty. But after 6months Renal USG is equally effective as DTPA scan.

We will continue this study for next 5 years to assess usefulness of Renal USG for long term post-operative follow-up.

\section{Conclusion}

Pelviureteric junction (PUJO) obstruction is by far the most common cause of pediatric hydronephrosis. Widespread use of antenatal USG has resulted in earlier diagnosis of hydronephrosis. But in this part of northern India as most of the children are presenting in age group of 1-6 years with symptoms due to PUJO, so our study concludes that there is need to improve quality and quantity of antenatal ultrasonography in this part of India.

The overall success rate with the Anderson Hynes Dismembered pyeloplasty repair is quite satisfactory; with all patients in our study showing improvement. However, there are no set criteria for follow-up or even for success of pyeloplasty.

This study shows that Renal USG is not as much informative as DTPA scan to assess functional outcome after 
pyeloplasty. But after 6months, it is equally effective as DTPA scan.

So, our study concludes that for resource poor countries like India, Renal USG can be used to assess functional outcome after pyeloplasty in pediatric age group; instead of costly \& scarcely available investigation like Renal DTPA scan.

\section{Abbreviation}

$\mathrm{PUJ}=$ Pelviureteric junction, $\mathrm{USG}=$ Ultrasonography, $\mathrm{AP}=$ Antero-posterior, DTPA= diethylene-triamine-pentaacetic acid.

\section{Conflict of Interest}

The authors declare that there are no conflicts of interest in this paper.

\section{Source of Funding}

None.

\section{References}

1. Josephson S. Experimental obstructive hydronephrosis in newborn rats. III. Long-term effects on renal function. J Urol . 1983;129:396400.

2. Josephson S, Ericson AC, Sjöquist M. Experimental Obstructive Hydronephrosis in Newborn Rats. VI. Long-Term Effects on Glomerular Filtration and Distribution. J Urol . 1985;134(2):391-5. do1:10.1016/s0022-5347(17)47184-9.

3. Josephson S, Robertson B, Claesson G, Wikstad I. Experimental obstructive hydronephrosis in newborn rats. I .Surgical technique and long-term morphologic effects. Invest Urol. 1980;17:478-83.

4. Josephsons WM, Ojteg G. Experimental obstructive hydronephrosis in newborn rats. II. Long-term effects on renal blood flow distribution. Scand J Urol Nephrol. 1982;16:179-85.

5. Koff SA. Pathophysiology of ureteropelvic junction obstruction Clinical and experimental observations. Urol Clin North Am. 1990;17:263-72.

6. Churchill BM, Feng WC. Ureteropelvic junction anomalies. In: Gearthard's Pediatric Urology. Saunders-Elsevier: Philadelphia; 2010. p. 248-71.

7. Groth TW, Mitchell ME. Ureteropelvic junction obstruction. In: Coran's Pediatric Surgery. Saunders-Elsevier: Philadelphia; 2012. p. 1411-26.

8. Pohl H, Rushton H, Park J, Belman A, Majd M. EARLY DIURESIS RENOGRAM FINDINGS PREDICT SUCCESS FOLLOWING PYELOPLASTY. J Urol. 2001;165(6 Part 2):2311-5. do1:10.1016/s0022-5347(05)66192-7.

9. Kirsch AJ, McMann LP, Jones RA, Smith EA, Scherz HC, GrattanSmith JD, et al. Magnetic Resonance Urography for Evaluating Outcomes After Pediatric Pyeloplasty. J Urol. 2006;176(4S):175561. doi:10.1016/j.juro.2006.03.115.

10. Salem YH, Majd M, Rushton HG, Belman AB. Outcome Analysis of Pediatric Pyeloplasty as a Function of Patient Age, Presentation and Differential Renal Function. J Urol. 1995;154(5):1889-93. do1:10.1016/s0022-5347(01)66819-8.

11. Hsi RS, Holt SK, Gore JL, Lendvay TS, Harper JD. National Trends in Followup Imaging after Pyeloplasty in Children in the United States. J Urol. 2015;194(3):777-82. do1:10.1016/j.juro.2015.03.123.

12. Zhou H, Li H, Zhang $\mathrm{X}$, Ma X, Xu H, Shi $T$, et al. Retroperitoneoscopic Anderson-Hynes dismembered pyeloplasty in infants and children: A 60-case report. Pediatr Surg Int. 2009;25:519_
23.

13. Blanc $\mathrm{T}$, Muller $\mathrm{C}$, Abdoul $\mathrm{H}$, Peev $\mathrm{S}$, Paye-Jaouen A, Peycelon M, et al. Retroperitoneal Laparoscopic Pyeloplasty in Children: Long-Term Outcome and Critical Analysis of 10-Year Experience in a Teaching Center. Eur Urol. 2013;63(3):565-72. do1:10.1016/].eururo.2012.07.051.

14. Minnillo BJ, Cruz JAS, Sayao RH, Passerotti CC, Houck CS, Meier PM, et al. Long-Term Experience and Outcomes of Robotic Assisted Laparoscopic Pyeloplasty in Children and Young Adults. J Urol. 2011;185(4):1455-60. doi:10.1016/].juro.2010.11.056.

15. Szavay PO, Luithle T, Seitz G, Warmann SW, Haber P, Fuchs $\mathrm{J}$, et al. Functional outcome after laparoscopic dismembered pyeloplasty in children. $\quad J$ Pediatr Urol. 2010;6(4):359-63. do1:10.1016/1.1purol.2009.10.015

16. Olsen LH, Rawashdeh YF, Jorgensen TM. Pediatric Robot Assisted Retroperitoneoscopic Pyeloplasty: A 5-Year Experience. J Urol. 2007;178(5):2137-41. do1:10.1016/j.juro.2007.07.057.

17. Valla JS, Breaud J, Griffin SJ, Sautot-Vial N, Beretta F, Guana $\mathrm{R}$, et al. Retroperitoneoscopic vs open dismembered pyeloplasty for ureteropelvic junction obstruction in children. J Pediatr Urol. 2009;5(5):368-73. do1:10.1016/].jpuro1.2009.02.202.

18. Braga LH, Lorenzo AJ, Bägli DJ, Mahdi M, Salle JP, Khoury $\mathrm{AE}$, et al. Comparison of Flank, Dorsal Lumbotomy and Laparoscopic Approaches for Dismembered Pyeloplasty in Children Older Than 3 Years With Ureteropelvic Junction Obstruction. J Urol. 2010;183(1):306-11. do1:10.1016/].juro.2009.09.008.

19. Barbosa JA, Kowal A, Onal B, Gouveia E, Walters M, Newcomer J, et al. Comparative evaluation of the resolution of hydronephrosis in children who underwent open and robotic-assisted laparoscopic pyeloplasty. J Pediatr Urol. 2013;9(2):199-205. doi:10.1016/1.jpuro1.2012.02.002.

20. García-Aparicio L, Blazquez-Gomez E, Martin O, Manzanares A, García-Smith N, Bejarano M, et al. Anderson-Hynes Pyeloplasty in Patients Less Than 12 Months Old. Is the Laparoscopic Approach Safe and Feasible? J Endourol. 2014;28(8):906-8. 601:-1089/end:20130704.

21. der Toorn F, van den Hoek J, Wolffenbuttel KP, Scheepe JR. Laparoscopic transperitoneal pyeloplasty in children from age of 3 years: Our clinical outcomes compared with open surgery. J Pediatr Urol. 2013;9(2):161-8. doi:10.1016/j.jpuro1.2012.01.007.

22. van den Hoek J, de Jong A, Scheepe J, van der Toorn F, Wolffenbuttel K. Prolonged follow-up after paediatric pyeloplasty: are repeat scans necessary? BJU Int. 2007;100:1150-2. do1:10.111/].1464 410x 200/201033x

23. Almodhen F, Jednak R, John-Paul C, Eassa W, Brzezinski A, ElSherbiny M, et al. Is Routine Renography Required After Pyeloplasty? J Urol. 2010;184(3):1128-33. ब01:10.1016/].juro.2010.05.017.

24. Cost NG, Prieto JC, Wilcox DT. Screening Ultrasound in Follow-up After Pediatric Pyeloplasty. Urology. 2010;76(1):175-9. do1:10.1016/1.urology.2009.09.094

25. Tveter KJ, Nerdrum HJ, Mjølnerød OK. The Value of Radioisotope Renography in the Followup of Patients Operated Upon for Hydronephrosis. J Urol. 1975;114(5):680-3. तबi:1016/s0022 5347(17)67116-7.

26. Psooy K, Pike JG, Leonard MP. Long-term Followup of Pediatric Dismembered Pyeloplasty: How Long is Long Enough? J Urol. 2003;169(5):1809-12. do1:10.1097/01.ju.0000055040.19568.ea

27. O'Reilly PH, Brooman PJC, Mak S, Jones M, Pickup C, Atkinson C, et al. The long-term results of Anderson-Hynes pyeloplasty. BJU Int 2001;87(4):287-9. do1:10.1046/].1464-410x.2001.00108.x

28. Chandrasekharam V, Srinivas M, Bal CS, Gupta AK, Agarwala S, Mitra DK, et al. Functional outcome after pyeloplasty for unilateral symptomatic hydronephrosis. Pediatr Surg Int. 2001;17(7):524-7. 001:10.

29. Anderson JC, Hynes W. Retrocaval ureter; a case diagnosed preoperatively and treated successfully by a plastic operation. $\mathrm{Br} \mathrm{J} \mathrm{Urol}$. 1949;21:209-1457.

30. Streem SB. Ureteropelvic junction obstruction.Open operative intervention. Urol Clin North. 1998;25:331-41. 


\section{Author biography}

RK Maurya, Professor

RK Tripathi, Professor

Ajay Kumar, Resident

Pinaki Ranjan Debnath, Professor
Vasu Gautam, Senior Resident

Arnab Kumar Saha, Senior Resident

Cite this article: Maurya RK, Tripathi RK, Kumar A, Debnath PR,

Gautam V, Saha AK. Outcome assessment for pyeloplasty in pediatric

age group on the basis of ultrasonography. IP Int J Med Paediatr Oncol $2021 ; 7(2): 57-62$ 